\title{
EFFECTS OF CLASSICAL SWINE FEVER VIRUS INFECTION ON THE PORCINE LEUKOCYTE SUBSETS
}

\author{
P. SOÓS ${ }^{1 *}$, H. J. SCHUBERT ${ }^{2}$ and K. R. DEPNER ${ }^{3}$ \\ ${ }^{1}$ Department of Microbiology and Infectious Diseases, University of Veterinary Science, \\ H-1581 Budapest, P.O. Box 22, Hungary; ${ }^{2}$ Institute of Immunology and ${ }^{3}$ Institute of \\ Virology, Hannover Veterinary School, Germany
}

(Received May 19, 1999; accepted October 20, 1999)

\begin{abstract}
The effects of classical swine fever (CSF) virus infection on the porcine leukocyte subsets were investigated by flow cytometry in acute, chronic and convalescent forms of the disease. The virus antigen could be first detected in the monocytes on postinfection (p.i.) day 10 while in the lymphocytes on p.i. day 13. It could be established that the ratio of $\mathrm{CD} 6+$ cells decreased until p.i. day 6, but afterwards it started to increase and reached different values. The $\mathrm{CD} 4+\mathrm{CD} 8+$, the CD8+ and the CD6- cells were obviously higher virus positive than the CD4+ and the CD4-CD8-subsets, but essentially all subsets could be infected. The ratio of CD8+ cells increased during the disease, while the number of double positive cells decreased, and that of the $\mathrm{CD} 4+$ cells was variable. The viral antigen could be detected in a lower percentage of the CD4+CD8+, CD8+, CD6+ and CD6- cells of the pigs affected with the chronic form of the disease than in those with the acute form. During the experiments no viral antigen could be detected in the leukocytes of the pig that became convalescent, though the changes in its leukocyte subsets were very similar to those seen in pigs in which the viral antigen could be detected. The studies have revealed that essentially all leukocyte subsets can be infected with the CSF virus, but in very different amounts.
\end{abstract}

Key words: Classical swine fever, flow cytometry, leukocyte subsets, CD markers

The course and the epizootiological properties of classical swine fever (CSF) first described in Ohio in 1833 have changed in the last decades. While in the first part of this century the epidemiology of the disease showed the typical, classical form, from the 1960s more and more data came to light in Germany, France and the Netherlands, suggesting that CSF could appear in different forms (Mengeling and Cheville, 1968; Liess et al., 1976). These forms manifest the mselves in chronic or fetopathogenic courses beside the acute form. A lifelong pe rsistent infection can result from in utero transplacental transmission of the CSF vi-

*E-mail: soos@novell.vmri.hu; Fax: +36 (1) 251-9260 
rus, and such pigs excrete the virus without showing any characteristic clinical signs (Van Oirschot and Terpstra, 1977).

These new clinical courses of the disease were tentatively attributed to viral virulence factors, but it was also observed that some so-called low virulent CSF virus strains could produce a typical, acute course too (Liess et al., 1976). It was also shown that different pig breeds infected with the same strain and dose of CSF virus developed acute, chronic and transient infection, providing evidence that breed-related genetic factors can influence the outcome of infection (Depner et al., 1997). Flow cytometric studies showed that CSF infections caused by strains of different virulence induced di $\mathrm{f}$ ferent immunological reactions (Markowska-Daniel et al., 1998).

The CSF virus replicates in the epithelial, endothelial and lymphoreticular cells (Cheville and Mengeling, 1969). The viral antigen can be first detected in the granulocytes and monocytes on p.i. day 10 (Summerfield et al., 1998). Immunohi stological and flow cytometric studies have pointed out that the drop of the leukocyte number as an early finding after infection is caused by depletion of the B lymph ocytes. This can be observed both in the lymphoid tissues and in the blood (Susa et al., 1992). Narita et al. (1996) found that the ratio of the CD4+ and CD8+ subsets i ncreased, while the so-called double positive $(\mathrm{CD} 4+\mathrm{CD} 8+)$ lymphocytes, which are typical of swine, showed a deficiency (Pauly et al., 1998).

The aim of this study was to compare the immunological changes during the acute and the chronic form of the disease.

Animals

\section{Materials and methods}

Five German Landrace and five Pietrain $\times$ German Landrace crossbred weaners were inoculated intranasally with the CSF virus isolate Visbek/Han95 in a dose of $750 \mathrm{TCID}_{50}$ (Table 1). Heparinized blood samples were collected from the vena cava cranialis twice weekly.

Table 1

Experimental animals

\begin{tabular}{ccl}
\hline Group 1 & \multicolumn{1}{c}{ Group 2 } & \multicolumn{1}{c}{ Control group } \\
\hline 5 German Landrace & 5 Pietrain $\times$ German Landrace & 1 German Landrace \\
& & 1 Pietrain $\times$ German Landrace \\
\hline
\end{tabular}

\section{Mononuclear cell separation}

Peripheral blood mononuclear cells (MNC) were obtained after Ficoll Isopaque (Cytogen, $\mathrm{g}=1.077 \mathrm{~g} / \mathrm{ml})$ density gradient centrifugation $(1100 \mathrm{~g}, 25 \mathrm{~min}$, $10^{\circ} \mathrm{C}$ ). Interphase cells were washed three times with PBS. 


\section{Preparation for flow cytometric analysis}

Monoclonal antibodies (mab) (Table 2) against surface structures and secondary reagents were used at appropriate dilutions $(20 \mu 1)$ in PBS- BN (PBS, $0.5 \% \mathrm{BSA}, 0.01 \% \mathrm{NaN}_{3}$ ). HC-34 anti-CSFV specific monoclonal antibody was used to detect viral antigen, SWC1 for detection of monocytes and T lymph ocytes, and SWC3 monoclonal antibody to detect swine monocytes. For indirect detection of the B lymphocytes anti-CD5 and anti-CD2 antibodies were used. All incubations and centrifugations during the procedure were made on ice to avoid capping and shedding. One to $5 \times 10^{6} \mathrm{MNC}$ were incubated in U-shaped 96-well microtitre plates with the respective monoclonal antibodies for $20 \mathrm{~min}$ on ice, washed twice with PBS-BN (200 g, $5 \mathrm{~min}$ ), and then incubated with se condary reagents. Unlabelled Mabs were detected with goat anti-mouse$\operatorname{IgG}(\mathrm{H} \& \mathrm{~L})-\mathrm{PE}$ (FIRMA, Germany). In case of three-colour fluorescence the cells were incubated further with biotinylated mabs which were detected with streptavidin-Cy5 (FIRMA, Germany). After membrane immunofluorescence the cells were washed once in PBS-BN and fixed in $100 \mu 11 \%$ paraformaldehyde (FIRMA, Germany) in PBS, $\mathrm{pH}$ 7.2, for $20 \mathrm{~min}$ at room temperature (RT). After centrifugation at $200 \mathrm{~g}$ for $5 \mathrm{~min}$ the cells were washed twice with PBS (200 g, $5 \mathrm{~min}$ ), and the final cell pellet was incubated for $20 \mathrm{~min}$ at RT in $25 \mu \mathrm{l}$ of the pestivirus-specific monoclonal antibody HC-34, directly coupled with FITC, diluted in saponin buffer (PBS-BN, 0.5\% saponin). After centrifugation (5 min, $200 \mathrm{~g}, \mathrm{RT}$ ) and discarding the supernatant the cells were resuspended in $200 \mu \mathrm{l}$ saponin buffer and kept at RT for further $30 \mathrm{~min}$. Finally the cells were spun down (200 g, $5 \mathrm{~min}, \mathrm{RT})$ and resuspended in $1 \mathrm{ml}$ PBS-BN.

Table 2

\begin{tabular}{ll}
\hline & Antibody panel \\
\hline A & B \\
1. 11/8/1+anti-mouse-IgG-PE (SWC1) & 1. MSA4+anti-mouse-IgG-PE (CD2) \\
2. B53B7 biotin+streptavidin-CY5 (CD5) & 2. B53B7 biotin+streptavidin-CY5 (CD5) \\
3. HC-34-FITC (CSFV) & 3. HC-34-FITC (CSFV) \\
C & D \\
1. 11/295/33+anti-mouse-IgG-PE (CD8) & 1. 74-22-15A+anti-mouse-IgG-PE (SWC3) \\
2. 74-12-4 biotin+streptavidin-CY5 (CD4) & 2. B53B7 biotin+streptavidin-CY5 (CD5) \\
3. HC-34-FITC (CSFV) & 3. HC-34-FITC (CSFV) \\
E & \\
1. A38B2+anti-mouse-IgG-PE (CD6) & \\
2. HC-34-FITC (CSFV) & \\
\hline
\end{tabular}


SOÓS et al

Flow cytometric analysis

For each measurement 10,000 events were acquired and gated for lymph ocytes and/or monocytes according to their light scatter characteristics. Evaluation of the data was performed with the software WinMDI.

\section{Results}

All animals became febrile after 6 days. All purebred and two crossbred pigs (II $/ 1, \mathrm{II} / 2$ ) developed the acute form of CSF. One purebred pig died on day 13 due to acute heart failure during the sampling (I/1). The other animals (I/2, $I / 3, I / 4$, $\mathrm{I} / 5$ ) died within the first month after infection. Two pigs of the crossbred group developed the chronic form of the disease and died 32 (II/3) and 45 (II/4) days post infection, respectively. One weaner of this group became convalescent after a mild transient infection (II/5). Both animals of the control group remained healthy wit $h$ out any symptoms during the experiment.

\section{Monocytes}

The viral antigen could be first detected in the monocytes (Fig. 1). A certain percentage of these cells proved to be virus positive on p.i. day 10. The kinetics of infection was very steep, because on p.i. day 13 , when the first lymphocytes became virus positive, the viral antigen could be found in $70-90 \%$ of the monocytes. This high percentage of positive monocytes persisted until the animals' death.
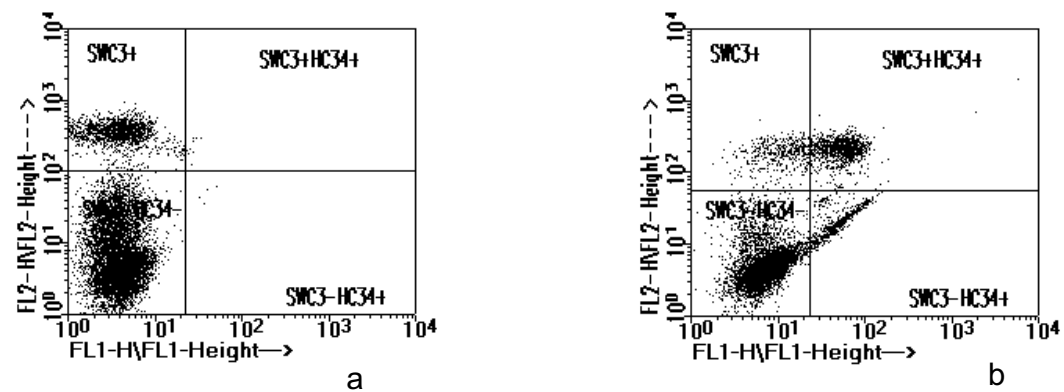

Fig. 1. SWC3+ healthy monocytes (a); monocytes infected with CSF virus antigen 13 days p.i. (b)

\section{Lymphocytes}

The viral antigen could be first detected in lymphocytes on p.i. day 13. The ratio of infected cells reached a maximum, and three groups could be formed a ccording to the level of this max imum: 
45-50\%: three animals with symptoms of acute CSF, which died on day 21 (I/3), 21 (II/1) and 24 (I/4), respectively;

25-35\%: one animal with chronic symptoms (II/3), two with acute form $(\mathrm{I} / 5, \mathrm{II} / 2)$, but one of them with ulcerative proctitis, which was typical in the chronic form. These pigs died on p.i. day 24 (I/5), 26 (II/2) and 32 (II/3);

10-20\%: one pig which died of the chronic form on p.i. day 45 (II/4).

One purebred pig (I/1) died too early, therefore no plateau could be esta blished.

In case of a purebred swine (I/2), which died on p.i. day 20 , the ratio of virus-positive lymphocytes continued to increase until death.

No viral antigen could be detected in the leukocytes of the convalescent pig (II/5).

CD6 cells

It could be established that the ratio of CD6+ cells decreased until p.i. day 6 (from $30-40 \%$ to $15-20 \%$ ), but afterwards it began to increase and reached diffe rent values depending on the form of disease. Sometimes it exceeded $70 \%$ in pigs that died of the acute form (Fig. 2). The CD6+ cells were less virus positive than the CD6- cells in every pig (Fig. 3). The ratio of virus-infected CD6+ and CD6lymphocytes increased before death.

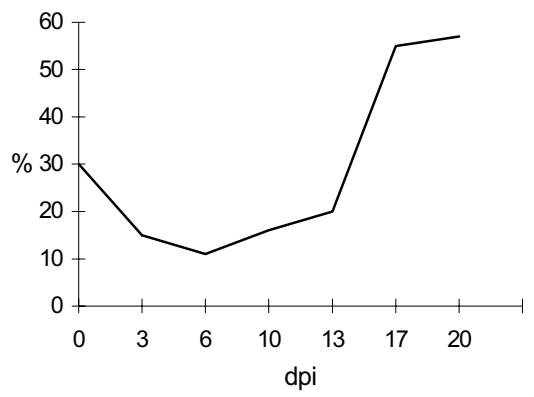

Fig. 2. Changes in the CD6+ subpopulation during acute CSF infection (II/1)

\section{CD4/CD8 cells}

Similar viral preference could be observed for the CD4 and CD8 subsets, because mainly in the later stages of the disease both the CD4+CD8+ and the CD8+ cells showed obviously higher virus positivity than the CD4+ and the CD4CD8 - subsets, but essentially all subpopulations could be infected. The CD8+ and the $\mathrm{CD} 4+\mathrm{CD} 8+$ cells were less virus positive in the pigs which died of the chronic form than in those that succumbed to the acute form of disease. The early strong decrease of CD4-CD8 - cells could be observed in every pig (Fig. 4). The ratio of $\mathrm{CD} 8+$ cells increased during the disease, while the number of double-positive cells decreased. The percentage of the CD4+ cells was var iable. 
During the experiment no viral antigen could be detected in the leukocytes of the pig which became convalescent, though the changes seen in the leukocyte subsets (CD6, CD4/CD8 cells) were very similar to those observed in cases where the viral antigen could be detected.

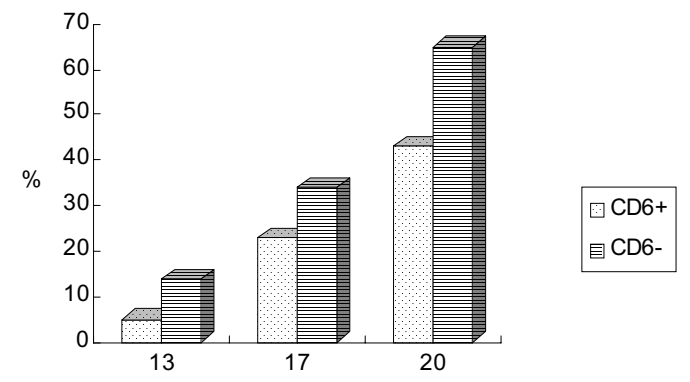

dpi

Fig. 3. Comparison of the ratios of virus-positive CD6+ and CD6- cells (I/2)
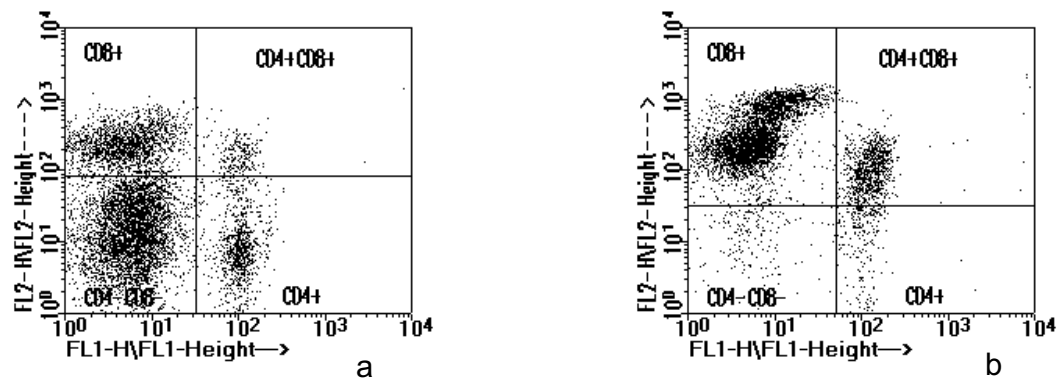

Fig. 4. The earliest sign of infection: the drastic decrease of CD4-CD8- cells as indirect evidence of the depletion of B lymphocytes. Control (a); infected animal (b). (No decrease of double-positive cells can be observed at this early stage.)

\section{Discussion}

The purpose of this experiment was to answer the following questions: (a) which leukocyte subsets are infected with CSF virus and at what time? (b) are these subsets permanently or just temporarily virus positive? (c) are there any di fferences among the subsets in terms of CSF virus i nfection?

The results obtained show that essentially every leukocyte subset can be i nfected with the CSF virus. It could be established that there is no selectively i nfected leukocyte subset, but there are subpopulations preferred by the CSF virus. However, the level of this preference can vary widely depending on the animals. 
Although no antibody was used to detect B lymphocytes, the early drastic drop of the CD5- and the CD4-CD8- cell ratios suggests that it is due to the depletion of B lymphocytes, which is in conformity with earlier results ( Susa et al., 1992). In agreement with the results of earlier studies (Narita et al., 1996), the ratio of CD8+ cells increased also in the present experiment, but in this study the percentage of $\mathrm{CD} 4+$ cells varied. The increasing ratio of $\mathrm{CD} 6+\mathrm{T}$ cells following their early $\mathrm{d}$ ecrease correlates with the role of these cells in MHC-restricted cytotoxic activity (Pauly et al., 1995; Pauly et al., 1996). For CD4+CD8+ (double-positive) cells, the number of which is high in swine compared to other animals, it was found that their ratio decreased during the infection, in line with the earlier results ( Pauly et al., 1998). In harmony with the results of Summerfield et al. (1998), the viral ant igen could be first detected in the monocytes on p.i. day 10, and the percentage of virus-positive cells very rapidly reached a high level. This was typical of both the chronic and the acute forms of infection. The viral antigen could be detected in the lymphocytes on p.i. day 13, which is consistent with the results of Pauly et al. (1998). Although every lymphocyte subset can be infected with CSF virus, certain subpopulations such as CD4+CD8+, CD8+ and CD6- cells obviously showed higher virus positivity than others. To explain this finding, the following hypoth eses can be suggested. The cell surface antigen structures binding CSF virus ( $i$ ) have genetic polymorphism; (ii) show varying levels of expression in the subsets; (iii) are genetically uniform but undergo modification after translation; ( iv) have an expression level depending on the activity of cells. These factors may be responsible for the great individual differences found in the ratios of virus-positive cells.

Differences were observed between the acute and the chronic form of disease in the immunological changes observed. The viral antigen could be detected in a lower percentage of lymphocytes in the chronic form, which observation concerned the CD4+CD8+, the CD8+, the CD6+ and the CD6- cells. Although the viral antigen could not be detected during the experiment in the convalescent pig, the subsets showed similar changes as in the virus-positive ones. This suggests that the immun osuppressive effect of CSF infection is not a direct consequence of the presence of $v$ iral antigen, since the lower responsiveness could be detected before the viral antigen appeared. The increasing ratio of $\mathrm{CD} 6+$ and $\mathrm{CD} 8+$ cells suggests that these subpopulations have an important role in the cellular immune response against CSF v irus infection.

\section{Acknowledgements}

The authors thank the Institute of Virology and the Institute of Immunology, Hannover Veterinary School for organisation of the experiment. Hybridomas were a kind gift of Dr. A. Saalmuller (BFA, Tubingen). Monoclonal antibodies were produced, purified and concentrated by I. Greiser-Wilke (Institute of Virology, Hannover Veterinary School), whose assistance is greatly appreciated. 


\section{References}

Cheville, N. F. and Mengeling, W. L. (1969): The pathogenesis of chronic hog cholera (swine fever). Histologic, immunofluorescent and electron microscopic studies. Lab. Invest. 20, 261-274.

Depner, K. R., Hinrichs, U., Bickhardt, K., Greiser-Wilke, I., Pohlenz, J., Moennig, V. and Liess, B. (1997): Influence of breed-related factors on the course of classical swine fever virus infection. Vet. Rec. 140, 506-507.

Liess, B., Frey, H. R., Prager, D., Hafez, S. M. and Roeder, B. (1976): The course of natural swine fever infection in individual swine and investigations on the development of inapparent SF infections. In: "Diagnosis and Epizootiology of Classical Swine Fever". Commission of the European Communities, Brussels. Publication EUR 5486. pp. 99-113.

Markowska-Daniel, I., Winnicka, A., Klucinski, W. and Pejsak, Z. (1998): Application of flow cytometry in the swine fever infections in piglets caused by strains of different virulence (in Polish). Medycyna Weterynaryjna 54, 258-264.

Mengeling, W. L. and Cheville, N. F. (1968): Host response to persistent infection with hog cholera virus. "Proceedings of the 72nd Annual Meeting of the US Animal Health Association". pp. 283-296.

Narita, M., Kawashima, K. and Shimizu, M. (1996): Viral antigen and B and T lymphocytes in lymphoid tissues of gnotobiotic piglets infected with hog cholera virus. J. Comp. Pathol. 114, 257-263.

Pauly, T., Elbers, K., Konig, M., Lengsfeld, T., Saalmuller, A. and Thiel, H. J. (1995): Classical swine fever virus-specific cytotoxic T-lymphocytes and identification of a T-cell epitope. J. Gen. Virol. 76, 3039-3049.

Pauly, T., Konig, M., Thiel, H. J. and Saalmuller, A. (1998): Infection with classical swine fever virus: effects on phenotype and immune responsiveness of porcine T lymphocytes. J. Gen. Virol. 79, 31-40.

Pauly, T., Weiland, E., Hirt, W., Dreyer-Bux, C., Maurer, S., Summerfield, A. and Saalmuller, A. (1996): Differentiation between MHC-restricted and non-MHC-restricted porcine cytolytic T-lymphocytes. Immunology 88, 238-246.

Summerfield, A., Hofmann, M. A. and McCullough, K. C. (1998): Low density blood granulocytic cells induced during classical swine fever are targets for virus infection. Vet. Immunol. Immunopathol. 63, 289-301.

Susa, M., Konig, M., Saalmuller, A., Reddehase, M. J. and Thiel, H. J. (1992): Pathogenesis of classical swine fever: B-lymphocyte deficiency caused by hog cholera virus. J. Virol. 66, $1171-1175$.

Van Oirschot, J. T. and Terpstra, C. (1977): A congenital persistent swine fever infection. I. Clinical and virological observations. Vet. Microbiol. 2, 121-132. 